\title{
Root cause analysis of medication errors at a multi-specialty hospital in Western India
}

\author{
Nilay D. Solanki*, Chaital Shah
}

Department of Pharmacology, Ramanbhai Patel College of Pharmacy, CHARUSAT, Changa, Gujarat, India

Received: 6 October 2013

Revised: 28 October 2013

Accepted: 29 October 2013

*Correspondence to:

Nilay D. Solanki,

Email:

nilaysolanki.ph@charusat.ac.in

(C) 2013 Solanki ND et al. This is an open-access article distributed under the terms of the Creative Commons Attribution Non-Commercial License, which permits unrestricted non-commercial use, distribution, and reproduction in any medium, provided the original work is properly cited.

\begin{abstract}
Background: Medication use is a complex process in a medical setting, it starts with physician prescribing, followed by nurse transcribing, pharmacist dispensing, medication administration, and patient monitoring. There is a definite role of clinical pharmacists in reduction of Medication errors by examining and evaluating its causes and communicate the results to physicians and caregivers. The aim of the present study was study of medication errors for the safety $\&$ the health benefit of the patient visiting multi specialty hospital.

Methods: The Observational study was carried out at in-patient appointments at multi specialty hospital during the period of June 2012 to April 2013 at Baroda.

Results: Total of 300 patients were observed out of which medication error has occurred in $117(39 \%)$ cases considering 62\% were males \& $38 \%$ female patients. Out of 117 cases $28 \%$ of transcription errors, $62 \%$ of prescription errors, $11 \%$ of dispensing errors \& $16 \%$ Administration errors. $51 \%$ of medication errors were occurring in the age group of 40-60. Root cause analysis showed that prescription error was due to Illegible handwriting, No dosage form prescribed, the Wrong Brand name prescribed; transcription error due to Wrong drug is transcribed; administrative error due to Wrong dose is administered, Drug administered through wrong route, Wrong drug is administered while dispensing error due to Urgent dispensation not done within 10 to 15 minutes, Wrong dose dispensed.

Conclusion: Most common medication errors were Prescription error \& Transcription error which accounts for almost $77 \%$ of the total error, which is according to Pareto 80:20 Principle.
\end{abstract}

Keywords: Medication error, clinical pharmacist, root cause analysis, Prescription error, Transcription error

\section{INTRODUCTION}

The National Coordinating Council for Medication has defined medication error as any preventable event that may cause or lead to inappropriate medication use or patient harm while the medication is in the control of the health care professional, patient or consumer, such events may be related to professional practice, health care products, procedures and systems including prescribing, order communication, product labeling, packaging, nomenclature, compounding, dispensing, distribution, administration, education, monitoring, and use. ${ }^{3}$ Medical mistakes that include medication errors have raised concerns about medication safety. Due to high consumption of medicines and self-treatment by all, especially the aging population, the issue of proper medication use and safety for public health concerns globally. Each country has a different approach towards medication event monitoring that is compliant with its own health care system. ${ }^{13}$ While in the long-term care (LTC) setting medication error are the most common unnoticed problem. Despite their frequency and potential clinical impact, most medication errors in LTC facilities remain unreported. Before better reporting systems can be developed to reduce clinically significant medication errors, it is necessary to understand how current medication error reporting systems function. ${ }^{14}$ Different types of medication errors are classified as Prescribing error, Dispensing error, Administration error, Transcription error. Prescribing errors are defined as the incorrect drug selection for a patient. Such errors can include the dosage, quantity, indication, or prescribing of a contraindicated drug. Lack of knowledge of the prescribed drug, its recommended dose, and of the patient details contributes to prescribing errors. ${ }^{4,5}$ Dispensing errors occur at any stage of the dispensing process, from the receipt of the prescription in the pharmacy to the supply of a dispensed medicine to the patient. Dispensing errors occur at a rate of 
$1-24 \%$ and include selection of the wrong strength or product. This occurs primarily with drugs that have a similar name or appearance. Lasix (Furosemide) and Losec (omeprazole) are examples of proprietary names which, when handwritten, look similar and further emphasize to prescribe generically. The Food and Drug Administration has insisted that the proprietary name of losses can be changed as a result of a number of fatalities associated with this confusion. ${ }^{6}$ Administration errors occur when a discrepancy occurs between the drug received by the patient and the drug therapy intended by the prescriber. Drug administration has long been associated with one of the highest risk areas in nursing practice, with the "five rights' (giving the right dose of the right drug to the right patient at the right time by the right route) being the cornerstone of nursing education. Drug administration errors largely involve errors of omission where the drug is not administered for a variety of reasons. ${ }^{7}$ Transcription error involves both the orders that are manually transcribed onto manual record like medication administration record (MAR) and electronically transcribed into computer systems. Types of transcription errors include wrong medication, time, dose, frequency, duration, verbal order misunderstanding, verbal orders not entered into system, orders entered into system that are discrepant from the medication history, order not manually transcribed onto MAR, wrong scheduling of doses in the MAR. ${ }^{8,9}$ There is a definite role of Clinical pharmacists in reduction of Medication Errors ${ }^{10}$ by Examining and evaluating the root causes of medication errors, analyzing aggregate data to determine trends, significance, frequency, outcomes of medication errors and communicate the results of the medication error program to healthcare practitioners, patients, and caregivers. Medication use is a complex process in a medical setting, it starts with physician prescribing, followed by nurse transcribing, pharmacist dispensing, medication administration, and patient monitoring. Many safeguards have been recommended for each of these phases, including the application of a computerized physician order entry system (CPOE), pointof-care unit dose-dispensing cabinet, and bar-coding technology. They can also play a leadership role in educating other healthcare professionals and advocating safe medication use. There is an important role for pharmacists, both in leading research efforts and in implementing best and safe practice in the hospital setting. The main objectives of this research work were to study different types of medication error by studying drug prescribing, dispensing, administration and transcription error by improving safety aspects of medication used by the patient; and study its root cause analysis at multi specialty hospitals, Baroda.

\section{METHODS}

\section{Study Design}

This study is Cross sectional and Observational study in which patients receiving medication during treatment were included and studied. Ethical approval was obtained from the institutional ethics committee for human research of Ramanbhai Patel college of Pharmacy, CHARUSAT, Changa and Permission from CEO of multispecialty hospital was taken regarding the study. The study was carried out at in-patient Department at the multi specialty Hospital during the period of June 2012 to April 2013. Patients of General Ward, Semi ward, ICU ward were considered for the study by selecting following criteria;

\section{Inclusion Criteria}

- Patients who were admitted to General Ward, Semi ward \& ICU ward irrespective of any sex, age \& conditions included in the study.

- Patients who were willing to participate in the study.

- Case files of the all patients admitted between periods of June 2012 to April 2013 were referred.

\section{Exclusion Criteria}

- Patients who were refusing to take medication.

- Patients who were not willing to participate in the study

- Patient Interaction was omitted during their stay in the hospital

Sample size: 300 cases were collected from a variety of diseased patient and accidental condition. Data were collected from the file of Inpatient department, Data scrutiny, statistical analysis and reporting procedures for pharmacy and quality department were done.

\section{Study Procedure}

I. Study of medication errors was conducted through a Cross sectional observational study conducted over a period ten months at General ward, Semi ward, ICU ward of multi-specialty Hospital at Baroda, Gujarat, India.

II. The case file with prescriptions were selected \& collected randomly of the inpatients admitted at multi specialty hospital. The data for the present study was collected by review method. During the study inpatients case records were reviewed, which includes patient's case history, diagnosis, physician medication order sheets, nurse medication administration records, laboratory investigations and report of other diagnostic tests. This information was documented in the patient profile form. Whenever Medication error is identified, during the review data from patient profile form was transferred to medication error reporting and documentation form.

III. All medication errors documented \& analyzed for following parameters such as demographic status of patients, age wise distribution of the errors, professionals involved in the errors, Causes of 
medication errors, Incidence of medication errors, types of medication errors and system wise distribution of errors.

IV. Medication errors are also assessed for its severity level by using the national coordination council for medication error reporting prevention proposed medication error index.

V. Each prescription is checked twice for medication errors. All the data were represented as percentages.

\section{MEDICATION ERROR SHEET}

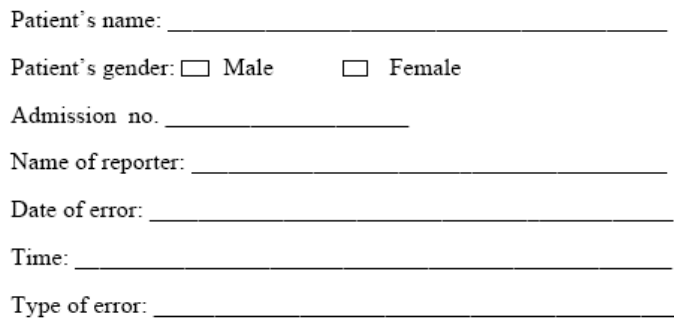

ANNEXURE CASE RECORD FORM

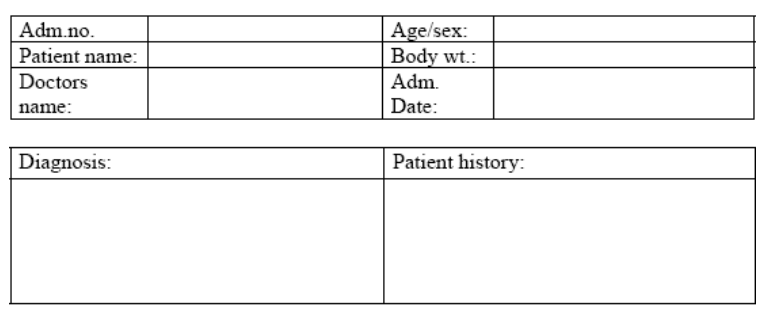

Drug Treatment Sheet:

\begin{tabular}{|l|l|l|l|}
\hline $\begin{array}{c}\text { Duration } \\
\text { of } \\
\text { treatment }\end{array}$ & Route & Prescribed drug & Freq. \\
\hline & & & \\
& & & \\
& & & \\
& & & \\
\hline
\end{tabular}

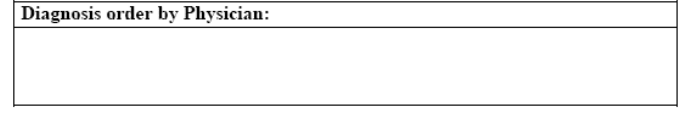

Drug Treatment Sheet: Cross Checking

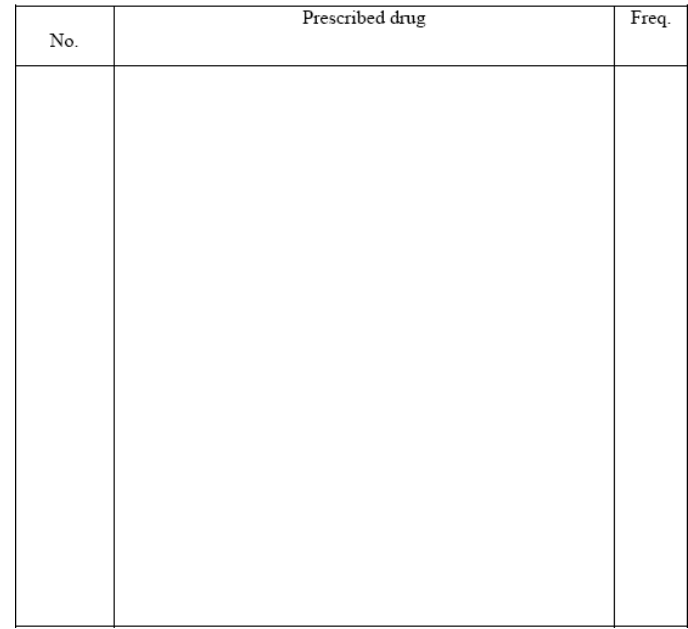

\section{RESULTS}

\section{Demographic status of the patients}

A total of 300 patients were considered \& analyzed in General ward, Semi ward, ICU ward Departments During the following study period. The demographic reports of our study showed total 300 patients were evaluated for Medication error, out of these $62 \%$ cases were Female patients $\& 38 \%$ cases were male patients.

\section{Medication Error Age -Wise Distribution}

The demographic reports of our study showed age-wise distribution (Tables 1), 4\% of patients were found below 20 years of age, $15 \%$ of patients were found between 21 to 40 years of age group, $51 \%$ of patients were found between 41 to 60 years of age group, and $29 \%$ of patients were found above 61 years of age group (Table 1).

Table 1: Age wise distribution of medication errors.

\begin{tabular}{|lll|ll|}
\hline No of patients & $\begin{array}{l}<20 \\
\text { years }\end{array}$ & $\begin{array}{l}\mathbf{2 0 - 4 0} \\
\text { year }\end{array}$ & $\begin{array}{l}\mathbf{4 0 - 6 0} \\
\text { year }\end{array}$ & $\begin{array}{l}>60 \\
\text { year }\end{array}$ \\
\hline $\begin{array}{l}300 \text { (Total number } \\
\text { of cases } \\
\text { of patients) }\end{array}$ & 16 & 73 & 126 & 85 \\
\hline $\begin{array}{l}117 \text { (cases in } \\
\text { which medication } \\
\text { errors were found) }\end{array}$ & $\begin{array}{l}5 \\
(4 \%)\end{array}$ & $\begin{array}{l}18 \\
(15 \%)\end{array}$ & $\begin{array}{l}60 \\
(51 \%)\end{array}$ & \begin{tabular}{l}
$(29 \%)$ \\
\hline
\end{tabular} \\
\hline
\end{tabular}

\section{Medication Error Wise Distribution of Male-Female Patients}

In Table 2 Transcription error occurrence rate gender wise accounts for 16 in male \& 12 in female patients, Prescription error accounts for 40 in male $\& 22$ in female 
patients, Administration error accounts for 11 in male \& 5 in female patients, while dispensation error accounts for 7 in male \& 4 in female patients.

\section{Table 2: Medication error wise distribution of male} and female patients.

\begin{tabular}{|llll|}
\hline $\begin{array}{l}\text { Types of } \\
\text { Medication Error }\end{array}$ & $\begin{array}{l}\text { Male } \\
\text { Patient }\end{array}$ & $\begin{array}{l}\text { Female } \\
\text { Patients }\end{array}$ & $\begin{array}{l}\text { All } \\
\text { Patients }\end{array}$ \\
\hline Transcription error & 16 & 12 & 28 \\
\hline Prescription error & 40 & 22 & 62 \\
\hline Dispensation error & 7 & 4 & 11 \\
\hline $\begin{array}{l}\text { Administration } \\
\text { error }\end{array}$ & 11 & 5 & 16 \\
\hline $\begin{array}{l}\text { Total error } \\
\text { Occurrence }\end{array}$ & 74 & 43 & 117 \\
\hline $\begin{array}{l}\text { Percentage }(\%) \\
\text { Distribution }\end{array}$ & $\begin{array}{l}62 \% \\
(74 / 117)\end{array}$ & $\begin{array}{l}38 \% \\
(43 / 117)\end{array}$ & $100 \%$ \\
\hline
\end{tabular}

\section{Root causes analysis of medication errors}

Root Cause Analysis (RCA) method is used for analysis of clinical data, as it is a way to identify the cause that is most directly responsible for errors. The Joint Commission on accreditation of Health Care Organizations (JCAHO) now requires all institutions to undertake RCA (Root Cause Analysis) of all sentinel events. The root cause analysis of different types of medication error showed various cases report found to be $117(39 \%)$ cases as in Table 4, factors responsible for Prescription error were Illegible handwriting holds for 21 (34\%), No dosage form prescribed accounts for $33(53 \%)$ \& Wrong Brand name prescribed holds for $8(13 \%)$ cases, factors responsible for Transcription error were Wrong drug is transcribed accounts for 28 (100\%), factors responsible for Dispensation error were Urgent dispensation not done within 10 to 15 minutes holds for 3 (27\%), Wrong dose dispensed accounts for 7(64\%) \& Wrong form of drug dispensed holds for $1(9 \%) \&$ factors responsible for Administrative errors were Wrong dose is administered holds for $9(56 \%)$, Drug administered through wrong route accounts for $1(6 \%)$, Wrong drug is administered holds for $5(31 \%)$ \& Drug administered which is not appropriate for Indication holds for $1(6 \%)$.

\section{DISCUSSION}

A medication error is an episode associated with use of medication that should be preventable through effective control system. The factors that increases the chance of medication errors are the attributes of the complex mechanisms involved in the prescribing, transcription dispensing and administration of drugs. Many authors have reported mechanisms for reducing medication error include reduced reliance on memory, improved asses to drug information, simplification, standardization and training. Substantial evidence suggests that pharmacists in decentralized patient care setting can reduce the frequency of medication errors.

In our study Total 117 cases out of 300 patients were found with the medication errors found which $39 \%$ of the total sample size. Similar results were obtained in the Prospective study conducted during the period of February 2012 to August 2012. It was concluded that in patient records of patients from six units of medicine department were reviewed during their stay in hospital and detected medication errors were documented and evaluated. A total of 500 cases of the patients was selected, among them $60.4 \%$ were male and $39.6 \%$ were females. $^{2}$

The demographic parameters of the present work were matched with the study conducted by Leelavati DA et al ${ }^{11}$ in 2012, they showed that higher incidence of medication errors in age group of 40-60 years, in our study also showed the highest incidence of medication errors in age group between 40-60 years. This can be attributed to the fact that the number of patients $(37.1 \%)$ visited the hospital during the study period was also ranged between $40-60$ years of the age groups. ${ }^{11}$

Our study showed (Table 3) that out of 117 cases of medication errors, Transcription error accounts for 28 (24\%), Prescription error holds maximum 62 (53\%), Dispensation error accounts for $11(9 \%) \&$ Administration error holds for $16(14 \%)$. Similar results were shown in one study where prescription errors were the most common among all the types of errors, ${ }^{2}$ which also support our study results of higher numbers of prescription error.

\section{Table 3: Type wise distribution of medication errors.}

\begin{tabular}{|c|c|c|c|}
\hline $\begin{array}{l}\text { Types of } \\
\text { Medication } \\
\text { Error }\end{array}$ & $\begin{array}{l}\text { Total } \\
\text { Cases }\end{array}$ & $\begin{array}{l}\text { Medicati } \\
\text { on error } \\
\text { Counts }\end{array}$ & $\begin{array}{l}\% \text { of Error } \\
\text { with reference } \\
\text { to total } \\
\text { Medication } \\
\text { error } \\
\text { occurred }\end{array}$ \\
\hline $\begin{array}{l}\text { Transcription } \\
\text { error }\end{array}$ & \multirow{4}{*}{300} & 28 & $24 \%(28 / 117)$ \\
\hline $\begin{array}{l}\text { Prescription } \\
\text { error }\end{array}$ & & 62 & $53 \%(62 / 117)$ \\
\hline $\begin{array}{l}\text { Dispensation } \\
\text { error }\end{array}$ & & 11 & $9 \%(11 / 117)$ \\
\hline $\begin{array}{l}\text { Administration } \\
\text { error }\end{array}$ & & 16 & $14 \%(16 / 117)$ \\
\hline $\begin{array}{l}\text { Total Error } \\
\text { Occurrence }\end{array}$ & & 117 & 100 \\
\hline
\end{tabular}

RCA is the multidisciplinary reviews of serious errors, which help to identify underlying causes or factors that may have contributed to the medication errors (Table 4). Similar results obtained in the study ${ }^{2}$ on root cause analysis where a total of 54 medication errors were identified, out of which $36(66.6 \%)$ errors were due to nursing staff, however $16.6 \%$ errors were due to Pharmacists. There were $20 \%$ errors due to illegible handwriting by a 
physician, $30 \%$ were due to high workload of hospital staff, where most of them post-gradates were involved in writing medication order. Our study result supports above mentioned data. In present study medication error due to illegible handwriting was found to be $34 \%$, supported by observational study ${ }^{2}$ in which $20 \%$ occurrence rate of errors, Secondly Medication error due to involvement of physicians showed $53 \%$, a study conducted by Karna et al ${ }^{2}$ showed $62.5 \%$ which again supports our study results.

Table 4: Root causes of medication errors.

\begin{tabular}{|ll|}
\hline Prescription error $62(53 \%)$ & $21(34 \%)$ \\
\hline Illegible handwriting. & $33(53 \%)$ \\
\hline No dosage form prescribed. & $8(13 \%)$ \\
\hline Wrong Brand name prescribed & $28(100 \%)$ \\
\hline Transcription error $28(24 \%)$ & \\
\hline Wrong drug is transcribed & $9(56 \%)$ \\
\hline Administration error 16 (14\%) & $1(6 \%)$ \\
\hline Wrong dose is administered & $5(31 \%)$ \\
\hline $\begin{array}{l}\text { A drug administered through } \\
\text { wrong route }\end{array}$ & $1(6 \%)$ \\
\hline Wrong drug is administered & \\
\hline $\begin{array}{l}\text { A drug administered which is not } \\
\text { appropriate for Indication }\end{array}$ & $3(27 \%)$ \\
\hline \begin{tabular}{l} 
Dispensation error $11(9 \%)$ \\
\hline $\begin{array}{l}\text { Urgent dispensation not done } \\
\text { within 10 to 15 minutes }\end{array}$
\end{tabular} & $7(64 \%)$ \\
\hline \begin{tabular}{l} 
Wrong dose dispensed \\
\hline \begin{tabular}{l} 
Wrong form of drug dispensed \\
\hline
\end{tabular}
\end{tabular} & \\
\hline
\end{tabular}

\section{CONCLUSION}

From this clinical observational study, we conclude that most of the medication errors were due to Prescription error \& Transcription error which were accounted for almost $77 \%$ of the total error. In nutshell almost $80 \%$ error was happening due to these two types of problems, which is according to the Pareto Principle (80:20 Principle). The root cause analysis of Medication error, Prescription error holds about 53\% \& the main causative factor was, no dosage form prescribed, while in case of transcription error $24 \%$ \& the main causative factor was the wrong drug transcribed.

\section{ACKNOWLEDGEMENTS}

We are highly grateful to Dr. R. H. Parikh, Principal, Ramanbhai Patel College of Pharmacy, CHARUSAT, Changa for providing constant encouragement \& financial support needed during this research work and we are also thankful to the staff of Sterling Hospital, Baroda, Gujarat for providing their support \& facility to carry out the work.

Funding: The study was financially supported by Ramanbhai Patel College of Pharmacy, CHARUSAT, Changa

Conflict of interest: None declared

Ethical approval: The study protocol was approved by the Institutional Ethics Committee-Human Research

\section{REFERENCES}

1. Saha D, Paul S. Glimpse of Pharmaceutical Education in India: History of Advances. International $\mathbf{J}$ of Pharmacy Teaching \& Practices. 2012; 3:387-404.

2. Karna K, Sharma S, Inamdar S, Bhandari A. The Impact Of Educational Intervention Strategies In Reducing Medication Errors In A Tartairy Care Teaching Hospital-A Second Intervention Study. International research J of Pharmacy. 2012; 1-17.

3. Parry K. Association For The Study Of Medical Education Report Of A Conference Held At The Royal College Of Physicians, London. 1987;21: 512-20.

4. Frenkiel S.Reporting of prescription from tertiary care hospital. Prescriber's Journal. 1999;39:51-8.

5. Medication errors are the single most preventable cause of patient injury, International J Pharm Pract. 1993;2:176-9.

6. Donaldson MS, et al, Finding of Medication Error, Am J Health-Syst Pharm, 1999;56:1319-25.

7. Ramanuj, Medication Error,Iran Pharm J, 1992; 5561.

8. Scott L, Aiken L, Dinges D, Drug Safety, Journal of Clinical pharmacy. 2000;22:321-33.

9. Prakash A \& Bhardwaj D. Medical audit. $2^{\text {nd }}$ Ed. New Delhi, India: Jaypee brothers medical publishers (P) Ltd; 2011.

10. Pharmacist's ASoH. ASHP guidelines on preventing medication errors in hospitals. Am J Hosp Pharm. 1993;50:305-14.

11. Hepler SL. Opportunities and responsibilities in pharmaceutical care, Indian Journal of Pharmaceutical Sciences. 2003; 34-60.

12. Desai R, Williams CE, Greene SB, Pierson S, Hansen RA. Medication Errors during patient transitions into nursing homes: characteristics and association with patient harm. The American journal of geriatric pharmacotherapy. 2011; 9:413-22.

13. Patel I, Balkrishnan R. Medication error management around the globe: an overview. Indian journal of pharmaceutical sciences. 2010; 72:539.

14. Handler SM, Nace DA, Studenski SA, Fridsma DB. Medication error reporting in long term care. The American journal of geriatric pharmacotherapy. 2004; 2:190.

doi:10.5455/2319-2003.ijbcp20131228

Cite this article as: Solanki ND, Shah C. Root cause analysis of medication errors at a multi-specialty hospital in Western India. Int J Basic Clin Pharmacol 2013;2:819-23. 